\title{
Association between recombinant human erythropoietin and quality of life and exercise capacity of patients receiving haemodialysis
}

\author{
Canadian Erythropoietin Study Group
}

\begin{abstract}
Objective-To determine whether recombinant human erythropoietin improves the quality of life and exercise capacity of anaemic patients receiving haemodialysis.
\end{abstract}

Design-A double blind, randomised, placebo controlled study.

Setting-Eight Canadian university haemodialysis centres.

Patients-118 Patients receiving haemodialysis aged 18-75 with haemoglobin concentrations $<90 \mathrm{~g} / \mathrm{l}$, no causes of anaemia other than erythropoietin deficiency, and no other serious diseases.

Interventions-Patients were randomised to three groups to receive placebo $(n=40)$, erythropoietin to achieve a haemoglobin concentration of $95-110 \mathrm{~g} / 1$ $(n=40)$, or erythropoietin to achieve a haemoglobin concentration of 115-130 $\mathrm{g} / \mathrm{l}(\mathrm{n}=38)$. Erythropoietin was given intravenously thrice weekly, initially at $100 \mathrm{units} / \mathrm{kg} / \mathrm{dose}$. The dose was subsequently adjusted to achieve the target haemoglobin concentration. All patients with a serum ferritin concentration less than $250 \mu \mathrm{g} / 1$ received oral or intravenous iron for one month before the study and as necessary throughout the trial.

Main outcome measures-Scores obtained with kidney disease questionnaire, sickness impact profile, and time trade off technique; and results of six minute walk test and modified Naughton stress test.

Results-The mean (SD) haemoglobin concentration at six months was $74(12) \mathrm{g} / \mathrm{l}$ in patients given placebo, $102(10) \mathrm{g} / 1$ in those in the low erythropoietin group, and 117 (17) $\mathrm{g} / \mathrm{l}$ in those in the high erythropoietin group. Compared with the placebo group, patients treated with erythropoietin had a significant improvement in their scores for fatigue, physical symptoms, relationships, and depression on the kidney disease questionnaire and in the global and physical scores on the sickness impact profile. The distance walked in the stress test increased in the group treated with erythropoietin, but there was no improvement in the six minute walk test, psychosocial scores on the sickness impact profile, or time trade off scores. There was no significant difference in the improvement in quality of life or exercise capacity between the two groups taking erythropoietin. Patients taking erythropoietin had a significantly increased diastolic blood pressure despite an increase in either the dose or number of antihypertensive drugs used. Eleven of 78 patients treated with erythropoietin had their sites of access clotted compared with only one of $\mathbf{4 0}$ patients given placebo.

Conclusions-Patients receiving erythropoietin were appreciably less fatigued, complained of less severe physical symptoms, and had moderate improvements in exercise tolerance and depression compared with patients not receiving erythropoietin. At the doses used in this trial there was a higher incidence of hypertension and clotting of the vascular access in patients treated with erythropoietin.

\section{Introduction}

Recombinant human erythropoietin is given to correct the anaemia of end stage renal disease $\mathrm{e}^{1-4}$ and thus decrease the likelihood of infections associated with transfusion and overload of iron. Uncontrolled studies suggest that erythropoietin improves general wellbeing, symptoms of fatigue, exercise tolerance, and cognitive and sexual function. ${ }^{6}$ Adverse effects that are attributed to erythropoietin in patients receiving haemodialysis include hypertension, flu-like symptoms, hyperkalaemia, seizures, and clotted vascular accesses. ${ }^{12+}$ These are common problems in such patients, and a causal role for erythropoietin has not been established.

We studied the effect of erythropoietin on the quality of life, exercise capacity, and putative adverse effects among anaemic patients receiving haemodialysis.

\section{Patients and methods}

We studied 118 anaemic patients who were receiving haemodialysis at 13 hospitals in eight Canadian university centres. Patients were stratified by hospital and randomised in blocks to receive placebo; erythropoietin at a dose adjusted to maintain the haemoglobin concentration at $95-110 \mathrm{~g} / \mathrm{l}$ (low erythropoietin group); or erythropoietin at a dose adjusted to maintain the haemoglobin concentration at 115-130 g/l (high erythropoietin group). The study was approved by the ethics committees of all the hospitals.

Patients were included in the study if they were aged 18 to 75 , had been clinically stable for three months, had had an average haemoglobin concentration of $<90 \mathrm{~g} / \mathrm{l}$ during the preceding three months, and had had haemodialysis three times a week in a hospital or self care unit. Patients were excluded if their anaemia was not caused by erythropoietin deficiency; their quality of life or exercise capacity was affected by factors other than renal failure; they were unable to perform a six minute walk test ${ }^{7}$; they would not be able to understand the questionnaires we were going to use because of language or intellectual difficulties; or they were unwilling or unable to give informed consent.

Erythropoietin was injected intravenously as a $10 \mathrm{ml}$ bolus at the end of each session of dialysis (three times a week). The dose in both groups receiving erythropoietin was initially 100 units $/ \mathrm{kg}$. When patients' haemoglobin concentration reached the lower end of the target range the dose was usually decreased by $25-50$ units $/ \mathrm{kg}$ at weekly intervals to maintain a stable concentration within the range. If the target concentration was not achieved by eight weeks in those in the low erythropoietin group or 12 weeks in those in the high erythropoietin group the dose was increased by $25-50$ units $/ \mathrm{kg}$. To avoid iron depletion patients with a serum ferritin concentration less than $250 \mu \mathrm{g} / \mathrm{l}$ were given iron orally or intravenously for one month before randomisation and as necessary throughout the trial.

To ensure that the study was double blind we established two teams of staff at each study centre. The unblinded team consisted of a doctor, a pharmacist,
Robarts Research Institute Ontario N6A 5KB, Canada.

BrMed f 1990;300:573-8 
and a data clerk and was responsible for adjusting the dose of erythropoietin, prescribing iron supplements or transfusions, and sending haematological data to the coordinating centre. The blinded team consisted of nurses in the dialysis unit and our study group and all doctors in the dialysis unit other than those in the unblinded team; this team carried out routine clinical care and recorded adverse reactions and other clinical events but did not have access to the results of haematological tests or know the dose of erythropoietin or placebo that each patient was receiving. The nurses in the study group administered tests to assess quality of life and exercise capacity.

All patients were followed up for six months, and outcome measures were assessed before randomisation and at two, four, and six months. The two main outcomes assessed were quality of life and exercise capacity. We thought that quality of life would be most effectively assessed by a questionnaire aimed specifically at patients receiving haemodialysis. To put the results into perspective, however, we included two global measures of quality of life.

We thus developed a kidney disease questionnaire using the methods suggested by Guyatt et al. ${ }^{8}$ We also used the sickness impact profile, which assesses health state based on behaviour and has been used in the national kidney dialysis and kidney transplant study, ${ }^{910}$ and the time trade off technique described by Churchill et $a l, "$ from which a "utility" is derived for each patient. These three measures of quality of life are described in more detail in the appendix.

To assess exercise capacity we used the six minute walk test and an exercise stress test. The six minute walk was conducted in enclosed corridors that were between 25 and $40 \mathrm{~m}$ long. Patients were instructed to walk from end to end, covering as much ground as possible in the allotted time. We gave patients an exercise stress test using a modified Naughton protocol $^{12}$ conducted in 11 two minute stages, with the speed of the treadmill increasing from 1.6 to $5.5 \mathrm{~km} / \mathrm{h}$ and the incline increasing from 0 to $16 \%$. If the patient was able to exercise for 22 minutes the test was continued for a further eight minutes at a speed of $5.5 \mathrm{~km} / \mathrm{h}$ and a gradual increase in the incline from $16 \%$ to $25 \%$. Standard encouragement was given during both exercise tests.

We calculated the size of sample that would ensure that a clinically important difference among the three groups at six months would be detected with the time trade off technique, sickness impact profile, and six minute walk test (the only outcome measures for which

TABLE I-Characteristics of patients at beginning of study into effects of low and high doses of erythropoietin. Values are means $(S D)$ unless stated otherwise

\begin{tabular}{lccc}
\hline & $\begin{array}{c}\text { Placebo } \\
\text { group } \\
(\mathrm{n}=40)\end{array}$ & $\begin{array}{c}\text { Low erythropoietin } \\
\text { group } \\
(\mathrm{n}=40)\end{array}$ & $\begin{array}{c}\text { High erythropoietin } \\
\text { group } \\
(\mathrm{n}=38)\end{array}$ \\
\hline Age (years) & $48(16)$ & $44(16)$ & $43(15)$ \\
No of men & 25 & 19 & 26 \\
No who were anephric & 6 & 13 & 10 \\
No who had had a transplant & 14 & 16 & 12 \\
Duration of haemodialysis (years) & $2 \cdot 5(3 \cdot 1)$ & $4 \cdot 6(4 \cdot 7)$ & $4 \cdot 4(5 \cdot 1)$ \\
No of transfusions during previous year & $7 \cdot 3(8 \cdot 3)$ & $6 \cdot 6(6 \cdot 8)$ & $5 \cdot 6(7 \cdot 4)$ \\
No dependent on transfusiont & 19 & 19 & 11 \\
Systolic blood pressure $(\mathrm{mm} \mathrm{Hg}) \neq$ & $143(19)$ & $137(22)$ & $143(21)$ \\
Diastolic blood pressure $(\mathrm{mm} \mathrm{Hg}) \neq$ & $80(12)$ & $78(14)$ & $78(12)$ \\
No receiving antihypertensive drugs & 10 & 13 & 12 \\
Haemoglobin $(\mathrm{g} / \mathrm{l})$ & $71(9)$ & $69(10)$ & $71(12)$ \\
Serum iron $(\mu \mathrm{mol} / \mathrm{l})$ & $19(14)$ & $18(9)$ & $22(15)$ \\
Serum ferritin $(\mu \mathrm{g} / \mathrm{l})$ & $703(866)$ & $1044(1690)$ & $1273(2303)$ \\
Median serum ferritin $(\mu \mathrm{g} / \mathrm{l})$ & 318 & 406 & 348 \\
Serum creatinine $(\mu \mathrm{mol} / \mathrm{l})$ & $1057(246)$ & $1090(260)$ & $1076(290)$ \\
Serum urea $(\mathrm{mmol} / \mathrm{l})$ & $28 \cdot 0(6 \cdot 0)$ & $27 \cdot 3(7 \cdot 0)$ & $27 \cdot 8(7 \cdot 2)$ \\
Serum potassium $(\mathrm{mmol} / \mathrm{l})$ & $5 \cdot 0(0 \cdot 6)$ & $5 \cdot 1(0 \cdot 6)$ & $5 \cdot 1(0 \cdot 7)$ \\
\hline
\end{tabular}

${ }^{\star} \mathrm{p}=0.07$ Among groups

+Patients who had received dialysis for one or more years were considered to be dependent on transfusion if they Peatients who had received dialysis for one or more years were considered to be dependent on transfusion if they
received six or more units of blood in the year before randomisation. Patients who had received dialvsis for less than received six or more units of blood in the year before randomisation. Patients who had received dialysis for less than
one year were considered to be dependent on transfusion if they had received more than two units of blood in the one year were considered to be depend
three months before randomisation.

three months before randomisation.
$\ddagger$ Placebo group $n=37$; low erythropoietin group $n=39$; high erythropoietin group $n=37$ data on variance were available before the study). ${ }^{13}$ We required 30 patients in each group (two tailed $x$ of 0.05 and a power of $90 \%$ ). Assuming a withdrawal rate of $25 \%$ due to renal transplantation, adverse effects, and concomitant events, this meant that we needed a sample of 120 patients.

The outcome variables were analysed only for patients who had completed all four evaluations (before randomisation and at two, four, and six months). Analysis of variance for repeated measures was used. The main hypothesis tested was that the mean response profiles of $i$. , ariables evaluated at the four time points were the same among the three groups. ${ }^{14}$ In addition to the overall comparison among the three treatment groups, two orthogonal contrasts were specified to compare the patients receiving placebo with the patients treated with erythropoietin (both groups) and the patients in the low erythropoietin group with those in the high erythropoietin group. Pearson's correlation coefficient was computed to examine the relation between the change in haemoglobin concentration and the change in quality of life and exercise capacity. Kendall's $\tau$ statistic and the corresponding $\mathrm{p}$ values were computed to detect any significant associations between the incidence of side effects and treatment with erythropoietin. ${ }^{15}$

\section{Results}

\section{PATIENT CHARACTERISTICS}

Forty patients were randomised to receive placebo, 40 low dose erythropoietin, and 38 high dose erythropoietin. Renal failure was due to glomerulonephritis (50 patients), pyelonephritis or interstitial nephritis (24), polycystic kidney disease (14), renal vascular disease (seven), chronic renal failure of unknown cause (three), nephritis induced by drugs (two), and other causes (18). Table I shows the characteristics of patients in the three groups at the beginning of the study; the three groups were comparable. Patients receiving placebo had been treated by dialysis for a shorter time than the two other groups $(p=0 \cdot 07)$. When age, duration of dialysis, whether patients had received a transplant or were anephric, dependence on transfusion, and antihypertensive treatment at the time of randomisation were examined with effect of treatment in the analysis the results of the unadjusted analysis were hardly affected.

\section{WITHDRAWALS FROM STUDY}

Nineteen patients were withdrawn during the study: eight in the placebo group (because of transplantation (five), non-compliance (one), reaction to transfusion (one), seizure and death (one)); six in the low erythropoietin group (transplantation (two), hypertension (one), hypertension and seizure (one), subarachnoid haemorrhage and seizure (one), pregnancy (one)); and five in the high erythropoietin group (transplantation (three), hypertension (two)). Six patients were withdrawn before the follow up at two months, and the 13 others were withdrawn before the follow up at four months. The patient who became pregnant continued to receive erythropoietin but had a spontaneous miscarriage at 11-12 weeks' gestation.

\section{CHANGES IN HAEMOGLOBIN CONCENTRATION}

Figure 1 shows the changes in haemoglobin concentration in the three groups. The mean (SD) haemoglobin concentration at six months was 74 (12) $\mathrm{g} / \mathrm{l}$ in the placebo group, $102(10) \mathrm{g} / \mathrm{l}$ in the low erythropoietin group, and 117 (14) g/l in the high erythropoietin group. The mean haemoglobin concentration reached the target range by six weeks in patients in the low erythropoietin group and by 


\begin{tabular}{|c|c|c|c|c|c|c|c|c|c|c|c|c|}
\hline & \multicolumn{3}{|c|}{$\begin{array}{l}\text { Placebo group } \\
\quad \mathrm{n}=32\end{array}$} & \multicolumn{3}{|c|}{$\begin{array}{l}\text { Low erythropoietin group } \\
\qquad(\mathrm{n}=34)\end{array}$} & \multicolumn{3}{|c|}{$\begin{array}{l}\text { High erythropoietin group } \\
\qquad(\mathrm{n}=33)\end{array}$} & \multicolumn{3}{|c|}{$\begin{array}{l}\text { Significance of } \\
\text { difference }\end{array}$} \\
\hline & Before & 2 At & $\begin{array}{c}\text { At } \\
6 \text { months }\end{array}$ & Before & 2 months & At & Before & $\begin{array}{c}\text { At } \\
2 \text { months }\end{array}$ & $\begin{array}{c}\text { At } \\
6 \text { months }\end{array}$ & $\begin{array}{l}\text { Among the } \\
\text { three } \\
\text { groups }\end{array}$ & $\begin{array}{c}\text { Erythropoietin } \\
v \\
\text { placebo }\end{array}$ & $\begin{array}{l}\text { High dose } v \\
\text { low dose } \\
\text { erythropoietin }\end{array}$ \\
\hline \multicolumn{13}{|l|}{ Kidney disease questionnaire: } \\
\hline Physical ${ }^{\star}$ & $4 \cdot 2$ & 4.7 & $4 \cdot 6$ & $3 \cdot 6$ & $4 \cdot 7$ & $5 \cdot 2$ & 3.9 & $5 \cdot 0$ & $5 \cdot 3$ & $<0.001$ & $<0.001$ & NS \\
\hline Fatigue & $4 \cdot 4$ & $4 \cdot 7$ & $4 \cdot 5$ & $4 \cdot 1$ & 4.9 & $5 \cdot 0$ & $4 \cdot 2$ & $5 \cdot 2$ & $5 \cdot 3$ & $<0.001$ & $<0.001$ & NS \\
\hline Relationships & 4.9 & $5 \cdot 1$ & $5 \cdot 0$ & 4.9 & $5 \cdot 3$ & $5 \cdot 5$ & 4.9 & $5 \cdot 4$ & $5 \cdot 5$ & 0.009 & 0.001 & NS \\
\hline Depression & $5 \cdot 0$ & $5 \cdot 2$ & $5 \cdot 1$ & $4 \cdot 7$ & $5 \cdot 0$ & $5 \cdot 1$ & $4 \cdot 8$ & $5 \cdot 3$ & $5 \cdot 5$ & $0 \cdot 045$ & 0.018 & NS \\
\hline Frustration & $4 \cdot 9$ & $4 \cdot 9$ & $4 \cdot 9$ & $4 \cdot 9$ & $5 \cdot 0$ & 4.9 & $4 \cdot 5$ & 4.8 & 4.9 & NS & NS & NS \\
\hline \multicolumn{13}{|l|}{ Sickness impact profilet: } \\
\hline Global & $10 \cdot 3$ & $8 \cdot 1$ & $7 \cdot 4$ & $12 \cdot 0$ & $8 \cdot 5$ & $6 \cdot 7$ & $12 \cdot 2$ & $6 \cdot 0$ & $4 \cdot 4$ & 0.029 & 0.024 & NS \\
\hline Physical & 4.9 & $3 \cdot 2$ & $4 \cdot 2$ & $6 \cdot 4$ & $4 \cdot 0$ & $2 \cdot 6$ & $6 \cdot 3$ & $3 \cdot 3$ & $2 \cdot 4$ & $0 \cdot 039$ & 0.005 & NS \\
\hline Psychosocial & $9 \cdot 1$ & $5 \cdot 9$ & $4 \cdot 8$ & $10 \cdot 9$ & $8 \cdot 1$ & $6 \cdot 0$ & $11 \cdot 8$ & $5 \cdot 2$ & $3 \cdot 0$ & NS & NS & NS \\
\hline Time trade off technique & $0 \cdot 42$ & $0 \cdot 46$ & $0 \cdot 42$ & $0 \cdot 49$ & $0 \cdot 51$ & $0 \cdot 51$ & 0.52 & 0.58 & 0.58 & NS & NS & NS \\
\hline Exercise stress test $($ minutes walked) & $11 \cdot 4$ & $13 \cdot 0$ & $13 \cdot 2$ & $11 \cdot 2$ & $14 \cdot 2$ & $14 \cdot 8$ & $16 \cdot 1$ & $19 \cdot 8$ & $19 \cdot 7$ & $0 \cdot 104$ & $0 \cdot 018$ & NS \\
\hline Six minute walk test $($ distance walked $(\mathrm{m})$ ) & 421 & 437 & 440 & 418 & 456 & 451 & 470 & 509 & 521 & NS & NS & NS \\
\hline
\end{tabular}

TABLE III -Symptoms defined by patients as being a problem associated with end stage renal disease before and two and six months after start of treatment with placebo or low or high doses of erythropoietin

\begin{tabular}{|c|c|c|c|c|c|c|c|c|c|c|c|c|c|}
\hline & \multirow[b]{2}{*}{$\begin{array}{c}\text { No } \\
\text { of } \\
\text { patients }\end{array}$} & \multicolumn{3}{|c|}{ Placebo group } & \multicolumn{3}{|c|}{ Low erythropoietin group } & \multicolumn{3}{|c|}{ High erythropoietin group } & \multicolumn{3}{|c|}{ Significance of difference } \\
\hline & & Before & 2 At & $\begin{array}{c}\text { At } \\
6 \text { months }\end{array}$ & Before & $\underset{2 \text { months }}{\mathrm{At}}$ & $\begin{array}{c}\text { At } \\
6 \text { months }\end{array}$ & Before & 2 months & $\begin{array}{c}\text { At } \\
6 \text { months }\end{array}$ & $\begin{array}{l}\text { Among the } \\
\text { three } \\
\text { groups }\end{array}$ & $\begin{array}{c}\text { Erythropoietin } \\
v \\
\text { placebo }\end{array}$ & $\begin{array}{l}\text { High dose } v \\
\text { low dose } \\
\text { erythropoietin }\end{array}$ \\
\hline Fatigue & 67 & $4 \cdot 1$ & $4 \cdot 6$ & $4 \cdot 1$ & $3 \cdot 1$ & $4 \cdot 3$ & $5 \cdot 4$ & $3 \cdot 7$ & $4 \cdot 9$ & $5 \cdot 0$ & $<0.001$ & $<0.001$ & 0.052 \\
\hline Decreased strength & 45 & $4 \cdot 1$ & $4 \cdot 7$ & $4 \cdot 2$ & $2 \cdot 8$ & $4 \cdot 0$ & $5 \cdot 3$ & $4 \cdot 0$ & $5 \cdot 3$ & $5 \cdot 3$ & $<0.001$ & $<0.001$ & 0.023 \\
\hline Sleeping abnormalities & 45 & $4 \cdot 0$ & $4 \cdot 3$ & $4 \cdot 5$ & $3 \cdot 8$ & $4 \cdot 0$ & $4 \cdot 0$ & $4 \cdot 3$ & $5 \cdot 3$ & $5 \cdot 6$ & NS & NS & NS \\
\hline Aching legs and bones & 35 & $3 \cdot 6$ & $4 \cdot 4$ & $4 \cdot 3$ & $3 \cdot 0$ & $4 \cdot 2$ & $4 \cdot 4$ & $4 \cdot 0$ & $5 \cdot 0$ & $5 \cdot 7$ & NS & NS & NS \\
\hline Shortness of breath & 20 & $3 \cdot 6$ & $4 \cdot 7$ & $4 \cdot 4$ & $4 \cdot 3$ & $5 \cdot 4$ & 5.9 & $4 \cdot 2$ & $5 \cdot 8$ & $5 \cdot 8$ & NS & NS & NS \\
\hline Sexuality & 18 & $4 \cdot 6$ & $4 \cdot 6$ & $5 \cdot 2$ & $3 \cdot 0$ & $4 \cdot 2$ & $4 \cdot 2$ & $3 \cdot 0$ & $3 \cdot 9$ & $5 \cdot 0$ & NS & NS & NS \\
\hline
\end{tabular}

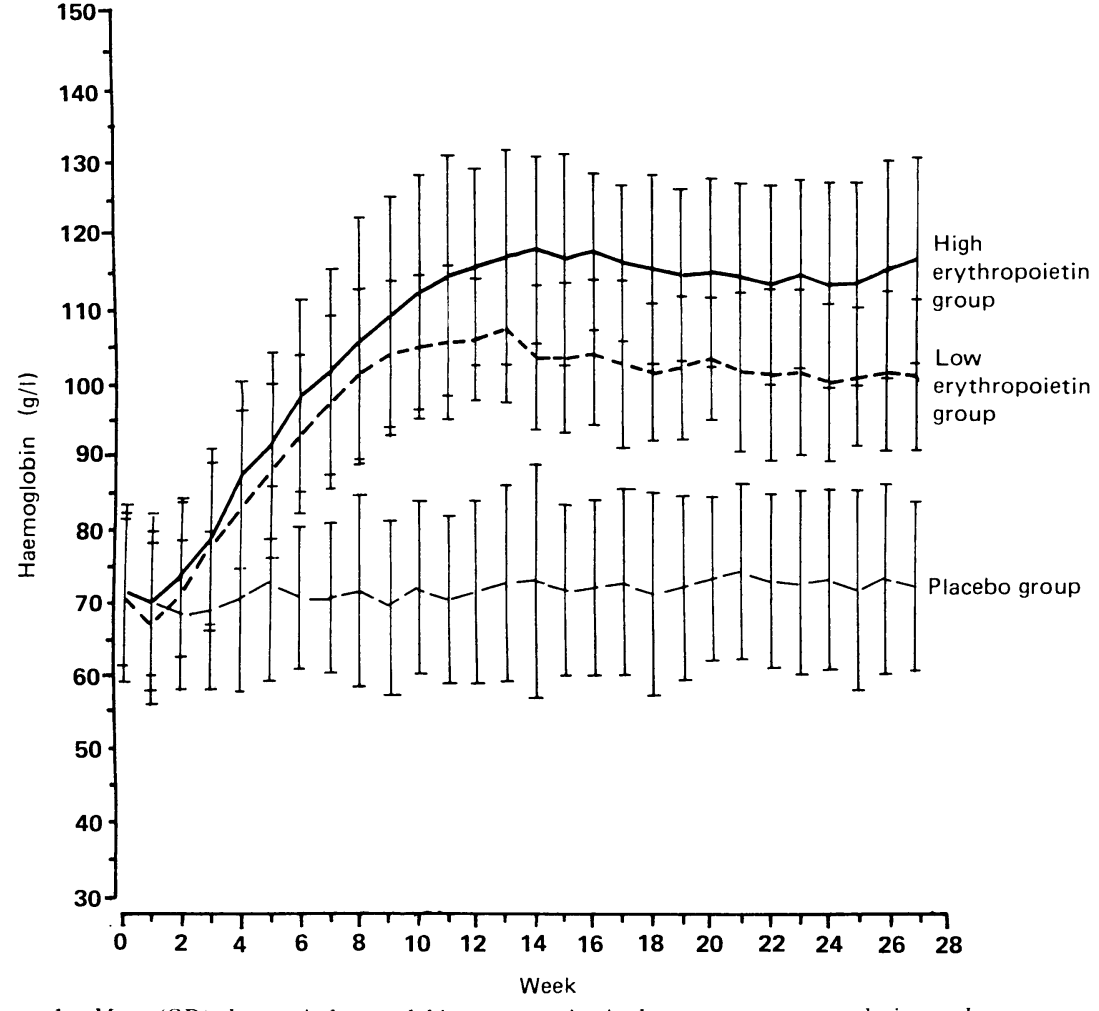

FIG 1-Mean (SD) changes in haemoglobin concentration in three treatment groups during study

11 weeks in patients in the high erythropoietin group. After eight weeks 23 patients in the placebo group, one in the low erythropoietin group, and one in the high erythropoietin group had had blood transfusions. The patient in the low erythropoietin group required transfusion because of gastrointestinal haemorrhage, and the patient in the high erythropoietin group had a transfusion during a hysterectomy.

The mean (SD) dose of erythropoietin at six months was 204 (167) units/kg/week in the low erythropoietin group and 248 (146) units $/ \mathrm{kg} /$ week in the high erythropoietin group. At six months iron supplements had been given to 11 patients in the placebo group, 12 in the low erythropoietin group, and 19 in the high erythropoietin group ( $p=0 \cdot 10$ among groups); they were given intravenously to four, five, and 11 of the patients, respectively. At six months the mean change in serum ferritin concentration from the value before treatment was significantly different among the groups $(+197(662) \mu \mathrm{g} / \mathrm{l}$ in the placebo group, $-341(769) \mu \mathrm{g} / \mathrm{l}$ in the low erythropoietin group, and $-241(953) \mu \mathrm{g} / \mathrm{l}$ in the high erythropoietin group; $\mathrm{p}=0 \cdot 02$ ).

\section{QUALITY OF LIFE AND EXERCISE CAPACITY}

The scores for quality of life before treatment were comparable among the three groups except for the time walked during the stress test $(p=0.02$, table II) and a trend for the section on physical symptoms in the kidney disease questionnaire $(p=0 \cdot 06)$. When these two variables were reanalysed with the value before treatment being included as a covariate factor the result for the stress test was more significant and no substantial change was found for the physical effects. Data from the four month visits on quality of life and exercise capacity were used to calculate significance but are not included in tables II or III as the improvements that occurred were generally apparent by two months, and none of the scores at four months were significantly better than those at six months.

Patients treated with erythropoietin showed a significant and clinically important improvement in their response to questions in the sections on fatigue and physical symptoms in the kidney disease questionnaire. There were also smaller improvements in their response to questions in the sections on relationships and depression, but no significant improvement with regard to the section on frustration.

Among the physical symptoms mentioned by the patient as most affecting his or her life there was a highly significant improvement in fatigue and strength in patients treated with erythropoietin (table III). 


\begin{tabular}{|c|c|c|c|c|c|c|c|c|c|c|c|c|c|c|c|}
\hline & \multicolumn{4}{|c|}{ Placebo group $(n=29)$} & \multicolumn{4}{|c|}{ Low erythropoietin group $(n=31)$} & \multicolumn{4}{|c|}{ High erythropoietin group $(n=32)$} & \multicolumn{3}{|c|}{ Significance of difference } \\
\hline & 0 & 2 & 4 & 6 & 0 & 2 & 4 & 6 & 0 & 2 & 4 & 6 & $\begin{array}{l}\text { Among the } \\
\text { three groups }\end{array}$ & $\begin{array}{l}\text { Erythropoietin } \\
v \text { placebo }\end{array}$ & $\begin{array}{l}\text { High dose } v \text { low dose } \\
\text { erythropoietin }\end{array}$ \\
\hline Systolic & 147 & 144 & 142 & 143 & 137 & 138 & 140 & 137 & 144 & 146 & 141 & 144 & NS & NS & NS \\
\hline Diastolic & 80 & 78 & 77 & 79 & 76 & 79 & 80 & 78 & 78 & 84 & 83 & 85 & 0.023 & $<0.001$ & 0.063 \\
\hline
\end{tabular}

TABLE V-Number of patients reporting various side effects while taking placebo or low or high doses of erythropoietin

\begin{tabular}{lccc}
\hline & $\begin{array}{c}\text { Placebo group } \\
(\mathrm{n}=40)\end{array}$ & $\begin{array}{c}\text { Low erythropoietin group } \\
(\mathrm{n}=40)\end{array}$ & $\begin{array}{c}\text { High erythropoietin group } \\
(\mathrm{n}=38)\end{array}$ \\
\hline Seizure & 1 & 2 & 0 \\
Clotting of vascular access & 1 & 4 & 7 \\
Clotting of tubing in dialysis machine & 4 & 4 & 4 \\
Pain in chest & 6 & 7 & 6 \\
Epistaxis or haemorrhage & 7 & 7 & 5 \\
Abnormal sense of taste & 6 & 13 & 4 \\
Headache & 19 & 2 & 13 \\
Redness of eyes & 0 & 9 & 3 \\
Flu-like symptoms & 12 & 8 & 9 \\
Aches in bone or muscle & 9 & & 12 \\
\hline
\end{tabular}

*Thrombectomy with or without revision of fistula was required in one patient in the placebo group, three in the low erythropoietin group, and six in the high erythropoietin group.

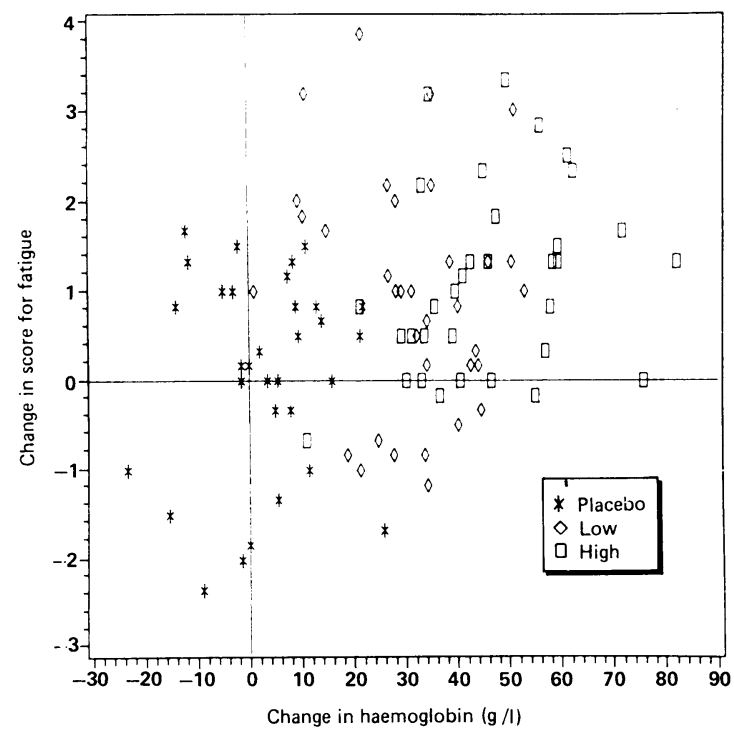

FIG 2-Relation between changes in score for fatigue on kidney disease questionnaire and changes in haemoglobin concentration in three treatment groups during study

Although erythropoietin seemed to cause an improvement in most of the other physical symptoms mentioned, this was not significant, perhaps because of the fairly small number of patients complaining of each symptom.

The global and physical scores on the sickness impact profile improved in the patients treated with erythropoietin compared with those given placebo (table II); the average improvement in the global score achieved in six months was 5.3 in the low erythropoietin group and $7 \cdot 8$ in the high erythropoietin group but only 2.9 in the placebo group. The sickness impact profile detected significant improvements $(p<0.05)$ in the response of patients to questions on body care and movement, home maintenance, ambulation, communication, and work among those treated with erythropoietin. There was no improvement in the aggregate psychosocial score or in scores for sleep and rest, emotional behaviour, mobility, social interaction, alertness behaviour, recreation and pastimes, or eating.

The time trade off technique showed no improvement in overall quality of life. The difference in the time walked in the exercise stress test between patients given erythropoietin and those given placebo was significant, but no significant improvement was found in results of the six minute walk test.

No significant difference between patients in the low and high erythropoietin groups was found in the change in any of the outcome measures assessed except decreased strength $(p=0 \cdot 02$, table III $)$.

CORRELATION BETWEEN CHANGES IN HAEMOGLOBIN CONCENTRATION AND CHANGES IN OUTCOME MEASURES

The mean haemoglobin concentrations before randomisation varied considerably among the patients, and some patients did not achieve their target concentration. We therefore assessed the correlation between the change in haemoglobin concentration and the change in quality of life and exercise capacity at six months. A significant correlation was found between the change in haemoglobin concentration and the change in the global, physical, and psychosocial scores on the sickness impact profile; all sections of the kidney disease questionnaire except that on frustration; and the time walked during the exercise test. The Pearson's correlation coefficients, however, were fairly low, the highest being observed with the scores for the sections on fatigue and physical symptoms in the kidney disease questionnaire $(r=0.32, p=0.001$ and $r=0.31, p=0.002$ respectively; fig 2 ).

\section{HYPERTENSION}

Table IV shows the mean systolic and diastolic blood pressures of the patients throughout the study. There was no significant difference in the change in systolic pressure throughout the study among the three groups. Diastolic pressure, however, was significantly increased in the patients treated with erythropoietin compared with those given placebo $(\mathrm{p}<0.001)$. The most striking increase was seen in the high erythropoietin group $(\mathrm{p}=0.006$, high erythropoietin $v$ placebo; and $\mathrm{p}=0.063$, high $v$ low erythropoietin). Among patients who completed the trial antihypertensive treatment was either started or increased in three patients given placebo compared with eight patients in the low erythropoietin group and 10 patients in the high erythropoietin group. The dose of antihypertensive drugs was decreased in one patient in the placebo group, none of the patients in the low erythropoietin group, and four patients in the high erythropoietin group. The association between erythropoietin treatment and an increase in the dose of antihypertensive drugs approached conventional significance $(p=0.06)$.

Four patients (two in the low erythropoietin group and two in the high erythropoietin group) had hypertension that was sufficiently severe for their doctor to withdraw them from the study (at one, two, 12 , and 13 weeks after randomisation). None of the patients had been taking antihypertensive drugs before the study. There were no permanent sequelae from these hypertensive episodes.

\section{OTHER SIDE EFFECTS}

Table $\mathrm{V}$ shows the incidence of other side effects. There was a positive association between treatment with erythropoietin and the incidence of clotting of the vascular access $(p=0.01)$ and eye redness $(p=0.04)$. There were no significant differences in the mean changes in serum concentrations of potassium, 
phosphorus, calcium, urea, and creatinine or white cell count among the groups throughout the study. At six months the platelet count had fallen by a mean (SD) of $5(39) \times 10^{9} / 1$ in the placebo group and increased by $25(64) \times 10^{9} / 1$ in the low erythropoietin group and $23(47) \times 10^{9} / 1$ in the high erythropoietin group $(\mathrm{p}=\mathbf{0} .005$, placebo $v$ both erythropoietin groups throughout study).

\section{BLINDING}

At the end of the study all patients were asked whether they thought they had received erythropoietin or placebo. Nineteen patients in the placebo group and 52 patients receiving erythropoietin correctly identified their treatment. Six of the placebo group thought that they had received erythropoietin while two of the patients receiving erythropoietin believed that they had been given placebo. The other patients could not say which they had received.

\section{Discussion}

Treatment with erythropoietin corrected the anaemia associated with end stage renal disease in patients being treated by haemodialysis. Generally, patients receiving erythropoietin were much less fatigued, complained of less severe physical symptoms, and had increased exercise tolerance compared with patients given placebo. There was no significant difference in quality of life or exercise tolerance between patients receiving low and high doses of erythropoietin. A significant correlation was found between changes in haemoglobin concentration and changes in quality of life and exercise capacity, but the correlation coefficient was modest. Although erythropoietin caused a significant improvement in quality of life and exercise capacity, many other factors, such as uraemia, bone disease, and the psychological burdens of haemodialysis, also adversely affect the wellbeing of such patients, and these factors may not be improved by erythropoietin.

The effect of erythropoietin on psychosocial function was less impressive than that on fatigue, physical symptoms, and exercise tolerance. Some significant (but moderate) improvements were seen in responses to the kidney disease questionnaire but not in the sickness impact profile. As the kidney disease questionnaire was developed for patients with renal failure it is not surprising that it was more responsive in our patients.

The two measures of overall quality of life yielded different results, an improved quality of life being detected in patients treated with erythropoietin by the sickness impact profile but not by the time trade off technique. The time trade off technique allows patients to give their own weighting to the physical, social, and emotional factors that affect their quality of life, while the sickness impact profile applies fixed weights that may not precisely have reflected the concerns of our patients. The time trade off technique, which asks patients how many years of their current health state they would be willing to give up to receive erythropoietin is a rigorous test; the fact that the time trade off score did not change in patients taking erythropoietin probably indicates that despite the drug many of the patients receiving dialysis still had several adverse effects from their disease. The time trade off technique has been successfully used to detect changes in quality of life, ${ }^{16}$ and complete insensitivity of the test is therefore unlikely to be the reason for the fairly constant scores in our study.

We examined several outcome measures, and thus multiple testing may possibly have caused some results to appear significant by chance. We expected the effect of erythropoietin on fatigue, however, to be the largest, and the high levels of significance we obtained make it extremely unlikely that the results occurred by chance alone.

It is difficult to recommend confidently a target haemoglobin concentration for patients treated with erythropoietin. In general, the patients' quality of life and exercise capacity rose with increasing haemoglobin concentration, but patients in the high erythropoietin group had a greater incidence of hypertension (and perhaps clotting of the vascular access) than patients in the other groups. Decisions on each patient's target haemoglobin concentration should be made clinically taking into account not only increased quality of life and exercise capacity but also the patient's likelihood of developing hypertension or thrombosis.

The ultimate clinical role of erythropoietin in the treatment of anaemic patients receiving haemodialysis will depend on the patient's need for transfusion, the ability of erythropoietin to prevent anti-HLA sensitisation, the cost of the drug, and the drug's efficacy and side effects in other populations receiving haemodialysis.

\section{Appendix}

\section{KIDNEY DISEASE QUESTIONNAIRE}

The kidney disease questionnaire is specific for patients with end stage renal disease and was developed from the methods described by Guyatt et al. ${ }^{8}$ We interviewed patients receiving haemodialysis and health care staff and reviewed existing quality of life variables. This generated a list of 130 items that could potentially have an adverse affect on the quality of life of the patients. Fifty patients receiving haemodialysis were then asked to rank these items in terms of their importance.

The items that were ranked most frequently and judged to be most important by the patients were included in the questionnaire. The final questionnaire consisted of 26 questions divided into five sections: physical symptoms, fatigue, depression, relationships, and frustration. In the section on physical symptoms each patient was asked to identify those physical symtoms or problems that most affected his or her life, and these were used for that patient throughout the study.

All questions were scored on a seven point Likert scale $(7=$ no problem, $1=a$ severe problem). For example, a question from the fatigue section, "How often in the past two weeks have you felt low in energy?" was accompanied by a choice of answers: (1) All the time; (2) most of the time; (3) a good bit of the time; (4) some of the time; (5) a little of the time; (6) hardly any of the time; and (7) none of the time.

A change in mean score of 0.5 in each section represented a minimal, clinically important difference, and a mean change of 1.0 represented a large clinical change. ${ }^{17}$

\section{SICKNESS IMPACT PROFILE}

The sickness impact profile is a questionnaire based on behaviour that contains 136 statements about dysfunction related to health in 12 types of activity: sleep and rest, eating, work, home management, recreation and pastimes, ambulation, mobility, body care and movement, social interaction, alertness, emotional behaviour, and communication. ${ }^{9}$ Some of these can be aggregated to give a physical score (body care and movement, mobility, and ambulation) and a psychosocial score (emotional behaviour, social interaction, ambulation, and communication). An overall score combining all questions can also be derived.

When answering the questionnaire the patients were asked to think about themselves that day and to 
determine which statements described them and were related to their health. The patient could answer only yes or no to each question. An example of a question about sleep and rest is, "I spend much of the day lying down in order to rest."

\section{TIME TRADE OFF TECHNIQUE}

The time trade off technique is used to derive a "utility," a score between 0 and 1 , in which 1 represents perfect health and 0 a state in which the patient is indifferent between life and death. ${ }^{11}$ With the help of visual aids patients were asked how many years of their current health they would be willing to forgo to achieve perfect health. For example, if a 36 year old patient stated that she was unable to choose between four years of perfect health and 40 years of her current health the utility of her current health state was $4 / 40=0 \cdot 10$ (she would be willing to give up 36 years of her current health to achieve four years of perfect health).

The Canadian Erythropoietin Study Group comprises the following groups. Executive committee: David Churchill, Paul Keown (chairman), Andreas Laupacis, Norman Muirhead, Dalice Sim, David Slaughter. Management committee: Paul Keown, Andreas Laupacis (chairman), Norman Muirhead, Beth Sarazin, Denise Short, Dalice Sim, David Slaughter, Cindy Wong. Study centres: Victoria General Hospital, Halifax, Nova Scotia (Allan Cohen ^ David Hirsch, Kailash Jindal); Royal Victoria Hospital, Montreal, Quebec (Paul Barre, ${ }^{\star}$ Andrew Gonda, Tom Hutchinson, Sarah Prichard, Denis Roy); Ottawa Civic Hospital and Ottawa General Hospital, Ottawa, Ontario (Andrew Lazarovits, ${ }^{\star}$ Steven Nadler, ${ }^{\star}$ Gerald Posen, Eli Rabin); St Joseph's Hospital, Hamilton, Ontario (Colin Barnes, David Churchill, ^ Sandra Donnelly, David Ludwin, Kinsey Smith); University Hospital and Victoria Hospital, London, Ontario, and Laurentian Hospital, Sudbury, Ontario (William Fay, David Hollomby, Tony Jevnikar, Paul Keown, Norman Muirhead ${ }^{\star}$; Health Sciences Centre and St Boniface Hospital, Winnipeg, Manitoba (Keevin Bernstein, Adrian Fine, John McKenzie, ${ }^{\star}$ Brian Penner, Brent Schacler, Ashley Thomson); Foothills Hospital, Calgary, Alberta (Ellen Burgess, Allan Jones, Henry Mandin ${ }^{\star}$; St Paul's and Vancouver General Hospitals, Vancouver,

British Columbia (Anthony Chiu, Gershon Growe, David Landsberg, John Price, John Shepherd, Roger Sutton, Linda Vickers, Ronald Werb). ${ }^{\star}=$ Principal investigators.

We thank the study nurses, data coordinators, and pharmacists at each of the centres; the support staff of Robarts Research Institute; Ulrike Kuprath, Patricia Laplante, Angela Mongul, David Slaughter, and other staff at Ortho Pharmaceutical (Canada) Ltd; and the patients. We also thank Janice Coffey for secretarial help.

1 Eschbach JW, Egrie JC, Downing MR, Browne JK, Adamson JW Correction of the anemia of end-stage renal disease with recombinan hum Correction of the anemia of end-stage renal dis
erythropoietin. N Engl F Med 1987;316:73-8

2 Winearls CG, Pippard MJ, Downing MR, Oliver DO, Reid C, Cotes PM Effect of human erythropoietin derived from recombinant DNA on the anaemia of patients maintained by chronic haemodialysis. Lance 1986;ii:1175-7.

3 Canadian Erythropoietin Study Group. A prospective, randomized, double-blind study of recombinant erythropoietin $(\mathbf{r}-\mathrm{Hu}-\mathrm{EPO})$ in chronic hemodialysis [Abstract]. Kidney Int 1988;33:218A.

+ Eschbach JW. The anemia of chronic renal failure: pathophysiology and the effect of recombinant erythropoietin. Kidney Int 1989;35:134-48.

Lundin AP. Quality of life: subjective and objective improvements with recombinant human erythropoictin therapy. Semin Nephrol 1989-9:22-9.

Schacfer RM, Kokot F, Wernze H, Geiger H, Heidland A Improwed lune R function in hemodialysis patients on recomb

7 Guyatt GH, Sullivan MJ, Thompson PJ, et al. The 6-minute walk: a new measure of exercise capacity in patients with chronic heart failure. Can Med Assoc f 1985;132:919-23.

8 Guyatt GH, Bombardier C, Tugwell P. Measuring disease-specific quality of life in clinical trials. Can Med Assoc f 1986;134:889-95.

9 Bergner M, Bobbitt RA, Carter WB, Gilson BS. The sickness impact profile: development and final revision of a health status measure. Med Care $1981 ; 19: 787-805$

10 Hart LG, Evans RW. The functional status of ESRD patients as measured by

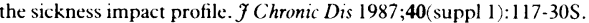

11 Churchill DN, Torrance GW, Taylor DW, et al. Measurement of quality of life in end-stage renal disease: the time trade-off approach. Clin Invest Med $1987 ; 10: 14-20$

12 Naughton J, Sevelius G, Balke B. Physiological responses of normal and pathological subjects to a modified work capacity test. I Sports Med Phys Fitness 1963:3:201-7.

13 Schwartz D, Flamant R, Lellouch J. Clinical trials. New York: Academic Press, 1980:137.

14 Winer BS. Statistical principles in experimental design. New York: McGrawHill, 1971:518-39.

15 Gibbons JD. Nonparametric statistical inference. New York: McGraw-Hill, 1971:209-26.

16 Mohide EA, Torrance (iW, Streiner DL, Pringle DM, Gilbert R. Measuring the wellbeing of family caregivers using the time trade-off technique. Clinical Epidemiology 1988;41:475-82.

17 Jaeschke R, Singer J, Guvatt G, Health status measurement: ascertaining the minimal clinically important difference. Controlled Clin Trials 1989:10:407 15.

Accepted 19 December 1989

\section{Short term increase in risk of breast cancer associated with full term pregnancy}

\author{
E M I Williams, L Jones, M P Vessey, \\ K McPherson
}

Department of Community Medicine and General Practice, Radcliffe Infirmary, Oxford OX2 6HE E M I Williams, MB, senior registrar

L Jones, BA, computer scientis M P Vessey, FFCM, professor $\mathrm{K}$ McPherson, PHD, lecturer

Correspondence to: $\mathrm{Dr}$ E M I Williams, Oxford Regional Health Authority, Old Road, Headington, Oxford OX3 7LF.

BrMed f 1990;300:578-9
Women who have their first full term pregnancy after age 35 are at higher risk of breast cancer than nulliparous women,' and the proportion of young women with breast cancer who have had children is higher than expected. ${ }^{2}$ These and other findings suggest that women who have full term pregnancies have a transiently increased risk of breast cancer that is followed by long term protection..$^{23}$ We applied the analysis described by Bruzzi et $a l^{3}$ to data obtained from an investigation which explored the relation between lifestyle factors and risk of breast cancer. ${ }^{+}$

\section{Patients, methods, and results}

Briefly, we recruited 1996 married women aged 2559 between 1980 and 1984 from seven hospitals. They comprised 998 patients with newly diagnosed breast cancer that had been confirmed histologically and 998 controls, who had been admitted electively with conditions not originally related to breast cancer.
Patients and controls were matched for admitting hospital and within five year age groups but not for parity. The present analysis aimed at detecting any increase in the risk of breast cancer shortly after a full term pregnancy. The interval between the date of diagnosis of breast cancer and the last term birth was studied. As this is related to age, age at first term birth, and parity these variables were adjusted for in the analysis.

Only women under 50 with two or more children were included to accord with the analysis by Bruzzi et $a l,{ }^{3}$ and this resulted in the study becoming unmatched (422 cases and 447 controls). The generalised interactive modelling (GLIM) package was used to estimate the maximum likelihood of effects. Graduated levels of exposure were assessed by linear trend tests.

The two groups were comparable in terms of centre of recruitment, which was ignored in subsequent analyses. An increased risk of breast cancer was associated with decreasing interval since last term birth $(p=0.021)$, increasing age at first term birth $(p=0.006)$, and decreasing parity $(\mathrm{p}=0.002)$ (table). When women aged under 40 and $40-49$ were considered separately the trends were broadly similar, although not all were significant.

\section{Comment}

Our results suggest that a transient increase in the risk of breast cancer occurs after full term pregnancy. 